\title{
ICEBERG RESPONSE TO SEA STATE
}

\section{(Abstract only)}

by

Olav Orheim,

(Norsk Polarinstitutt, Postboks 158, 1330 Oslo Lufthavn, Norway)

Peter Wadhams and Monica Kristensen

(Scott Polar Research Institute, University of Cambridge, Cambridge CB2 1ER, England)

\section{ABSTRACT}

Data from instruments placed on tabular Antarctic icebergs show that they flex, heave, and roll in response to ocean waves. One iceberg was monitored for 13 months in the Weddel1 Sea by an automatic data collection platform deployed by the Norwegian Antarctic Research Expedition 1978-79. The temperature sensors demonstrated burial by snow-fall during autumn and winter, but melting during the following summer

led to a net annual surface mass balance of $-0.1 \mathrm{~m}$ water equivalent and to snow and firn temperatures being raised to the melting point. Strain and tilt instruments showed flexure and tilt with main frequencies around 15 to $20 \mathrm{~s}$, but short sampling periods made it difficult to conduct comprehensive statistical analysis of the data.

The encouraging results from automatic stations led to direct experiments in January 1981 by a party comprising the three authors, working from

HMS Endurance. In situ studies of three icebergs included measurements of surface strain in three directions, tilt in two directions, vertical heave and rotation, and concurrent measurements of the sea state by Waverider buoy (Kristensen and others 1981) All icebergs were bending at the surface, and heaved and rolled in response to the long component of the incident waves (10 to $15 \mathrm{~s}$ and longer). Typical values were: $5 \times 10^{-8}$ strain, $0.1 \mathrm{~m}$ heave, and $\pm 1 \times 10^{-4}$ rad tilt. Resonant responses with 1 arger amplitudes and at longer periods were observed both in heave and tilt. The iceberg acts essentially as a low-pass filter on the sea state, but with different response periods to different types of motion.

Measurements of iceberg heading by the automatic stations and by in situ measurements show that the icebergs readily rotate in the horizontal plane, and that the magnitude and direction of rotation is sensitive to changes in wind conditions.

REFERENCE

Kristensen M, Orheim O, Wadhams P 1981 Field experiments on Antarctic tabular icebergs. Polar Record 20(128): 445-448
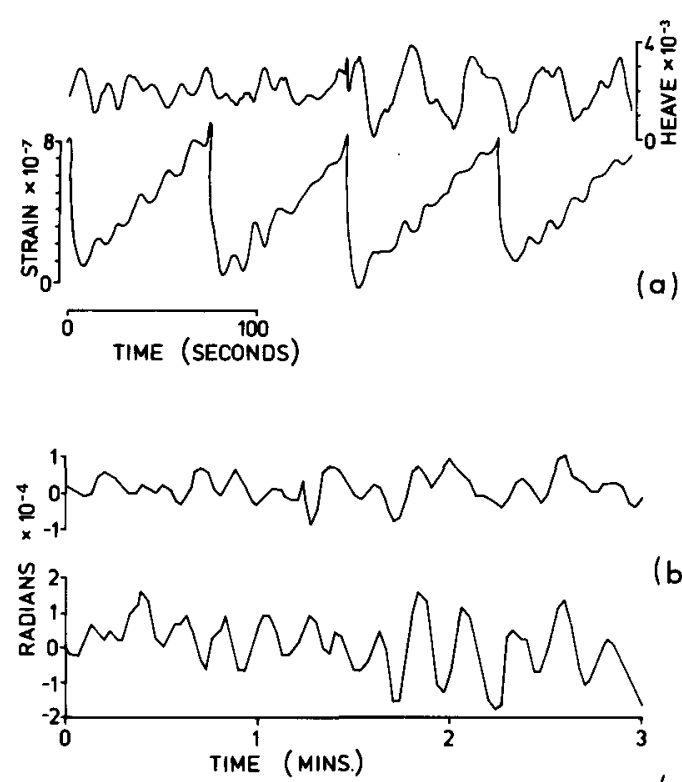

(b)

(c)

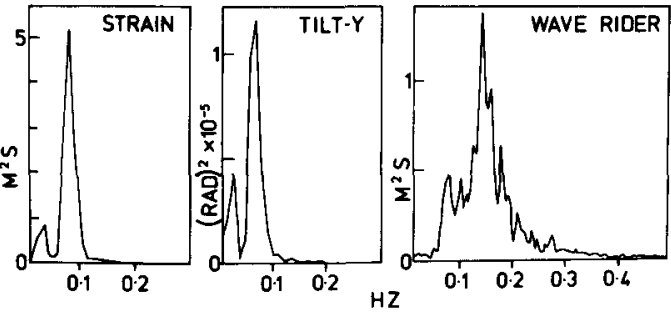

Fig.1. Data obtained from iceberg 2 (dimensions $1100 \times 500 \mathrm{~m}$, samples 11 January 1981 at $58^{\circ} 55^{\prime} \mathrm{s}$, $\left.26^{\circ} 06^{\prime} \mathrm{W}\right)$ and iceberg $3(1300 \times 1200 \times 900 \mathrm{~m}$ triangle, 14 January $\left.1981,60^{\circ} 01^{\prime} \mathrm{S}, 43^{\circ} 15^{\prime} \mathrm{W}\right)$.

(a) Concurrent heave and strain records (berg 2), showing an outbreak of resonant bobbing at $40 \mathrm{~s}$ period. Sawtooth on strain record is thermal drift and rezeroing.

(b) Tilt records (berg 3 ); upper record is parallel with long axis, lower record is at right angles (not concurrent).

(c) Power spectra of strain and tilt (berg 2) compared with the spectra of ambient wave energy, showing responses at 15 and $40 \mathrm{~s}$ period. 
